\title{
Segurança no trabalho: $O$ uso de técnicas bibliométricas
}

Este artigo explora o acervo dos periódicos da Associação Nacional de Pós-Graduação em Administração (ANPAD), especificamente no evento Encontro Nacional de Gestão de Pessoas e Relações de Trabalho/EnGPR, da ANPAD, no período de 2007 a 2016, relacionados com o tema Qualidade de Vida no Trabalho/QVT. O presente estudo tem como objetivo analisar a produção científica acadêmica de trabalhos recentes sobre a temática segurança no trabalho, e ampliar a discussão sobre este assunto, utilizando as técnicas bibliométricas. Especificamente, contextualizar e caracterizar aspectos sobre a qualidade de vida no trabalho, discutir sobre higiene e segurança no trabalho, e detalhar como estão sendo abordados os estudos sobre QVT. A metodologia utilizada foi à pesquisa descritiva, quantitativa, bibliográfica com o uso de bibliometria. Os resultados encontrados demostraram que os estudos apresentados na EnGPR sobre a qualidade de vida no trabalho tiveram como foco principal a higiene do trabalho, enfatizando a satisfação no trabalho. Deixando em segundo plano, os aspectos relacionados à segurança no trabalho, algo de fundamental importância nos dias atuais.

Palavras-chave: Qualidade de vida no trabalho; Estresse; Satisfação.

\section{Safety at work: The use of bibliometric techniques}

This article explores the collection of periodicals of the National Association of Postgraduate in Administration (ANPAD), specifically in the event National Meeting of People Management and Labor Relations / EnGPR, from ANPAD, from 2007 to 2016, related to the theme Quality of Life at Work / QVT. The present study aims to analyze the academic scientific production of recent works on the topic of occupational safety, and to expand the discussion on this subject, using bibliometric techniques. Specifically, to contextualize and characterize aspects about the quality of life at work, discuss about hygiene and safety at work, and to detail how studies on QWL are being approached. The methodology used was descriptive, quantitative, bibliographical research using bibliometrics. The results showed that the studies presented in the EnGPR on the quality of life at work had as main focus the work hygiene, emphasizing the satisfaction in the work. Leaving in the background, the aspects related to safety at work, something of fundamental importance in the present day.

Keywords: Quality of life at work; Stress; Satisfaction.

\section{Topic: Recursos Humanos}

Reviewed anonymously in the process of blind peer
Received: 11/01/2019

Approved: 21/04/2019
João Batista Ferreira (iD)

Faculdade Cidade de Coromandel, Brasil

http://lattes.cnpq.br/2559008946569327

http://orcid.org/0000-0002-9264-3112

coordenacaoadmfcc@hotmail.com
Referencing this:

FERREIRA, J. B.. Segurança no trabalho: O uso de técnicas bibliométricas. Revista Brasileira de Administração Científica, v.9, n.1, p.32-45, 2018. DOI: http://doi.org/10.6008/CBPC2179$\underline{684 X .2018 .001 .0003}$ 


\section{INTRODUÇÃO}

A Segurança do Trabalho pode ser entendida como o conjunto de medidas adotadas, visando minimizar os acidentes de trabalho, doenças ocupacionais, bem como proteger a integridade e a capacidade de trabalho das pessoas envolvidas (PEIXOTO, 2011). Neste sentido, compreender e aprofundar neste assunto é algo e de grande relevância acadêmica e profissional, assim, esta pesquisa objetivou analisar a produção científica acadêmica de trabalhos recentes sobre a temática segurança no trabalho, e ampliar a discussão sobre este assunto.

Especificamente, contextualizar e caracterizar aspectos sobre a qualidade de vida no trabalho, discutir sobre higiene e segurança no trabalho, e detalhar como estão sendo feitos os estudos sobre a Qualidade de Vida no Trabalho/QVT, por meio de técnicas bibliométricas. Como fonte de pesquisa foi usado os eventos da Associação Nacional de Pós-graduação e Pesquisa em Administração/ANPAD, pois desenvolve um relevante trabalho na produção de conhecimento no campo de administração e áreas afins no Brasil, em especial no evento Encontro Nacional de Gestão de Pessoas e Relações de Trabalho/EnGPR, da ANPAD, no período de 2007 a 2016.

Este artigo é estruturado em cinco (5) sessões distintas, incluindo a introdução, na sessão dois (2) a fundamentação teórica, abordando gestão de pessoas, qualidade de vida no trabalho, higiene e segurança no trabalho; na sessão três (3) apresentar os métodos; na sessão quatro (4) os resultados; e em sequência a conclusão e referências.

\section{REVISÃO TEÓRICA}

\section{Gestão de Pessoas}

Chiavenato (2014) relata que a gestão é formada por pessoas e organizações, as pessoas passam boa parte de suas vidas trabalhando dentro das organizações, estas dependem daquelas para poderem funcionar e alcançar sucesso, pois, de um lado, o trabalho toma considerável tempo das vidas e dos esforços das pessoas, que ele depende para a subsistência e sucesso pessoal. Segundo Ferreira et al. (2017) para que haja uma Gestão de Pessoas (GP) é necessário que exista um trabalho entre pessoas e empresas, para gerir pessoas é preciso muito mais capacidade e dedicação do que no passado, pois, com o mundo globalizado, as empresas estão em busca de colaboradores que venham somar com elas, e não que apenas desempenhem suas funções. A gestão de pessoas é a auxiliadora para que tudo isso aconteça de forma correta.

Falco et al. (2012) enfatizam que as empresas que só visam lucro, produção e redução de gastos, sem se preocupar com as pessoas, para além de suas funções e de seus trabalhos, perdem em planejamento, em comunicação e o principal: em motivação profissional. Hoje em dia as organizações que conquistam sucesso são as que valorizam a qualidade dos trabalhos e apresentam ações voltadas para a motivação e satisfação dos colaboradores.

Ferreira et al. (2017) inferem que as organizações perceberam que para serem bem-sucedidas têm que valorizar de forma especial seus colaboradores, fazer com que todo sucesso da empresa fosse também 
revertido de alguma forma em benefício para os mesmos. A gestão de pessoas pode ser subdividida em processos, mas para Chiavenato (2014) os processos de gestão de pessoas podem ser subdivido em agregando pessoas, aplicando pessoas, recompensando pessoas, desenvolvendo pessoas, mantendo pessoas e monitorando pessoas.

Sabe-se que agregar pessoas envolve recrutamento e seleção; aplicar pessoas está relacionado ao desenho, analise e descrição dos cargos na empresa; recompensar pessoas envolve a remuneração e os incentivos pessoais; desenvolver pessoas envolve a capacitação; monitorar pessoas diz respeito ao controle e acompanhamento das atividades e por fim manter pessoas, que é o foco do trabalho em questão. Na visão de Falco et al. (2012) manter pessoas é uma maneira prática que as empresas encontraram para satisfazer seus colaboradores, proporcionando segurança e boas condições físicas e mentais para o exercício de suas atividades. Como o foco deste estudo envolve o processo de manter pessoas, o mesmo será discutido nas próximas seções.

\section{Qualidade de Vida no Trabalho - QVT}

Segundo Chiavenato (2014), o conceito de QVT refere-se à preocupação com o bem-estar geral e a saúde dos colaboradores no desempenho de suas atividades, sendo assim que assimila duas posições antagônicas: de um lado, a reinvindicação dos colaboradores quanto ao bem-estar e a satisfação no trabalho; de outro, o interesse das organizações quanto aos seus efeitos positivos e potenciadores sobre a produtividade e a qualidade no trabalho. Na visão de Pazini et al. (2009) a gestão da qualidade de vida no trabalho é uma importante ferramenta para as organizações, pois é através destes programas que se consegue obterem melhores resultados, almejando o bem-estar do indivíduo na organização, promovendo a satisfação no ambiente de trabalho e a retenção dos talentos nas instituições.

Chiavenato (2014) aborda que ao lado da higiene e da segurança do ponto de vista físico e ambiental, existe o bem-estar psicológico e social. A expressão qualidade de vida no trabalho (QVT) foi fundada por Louis Davis na década de 1970 quando desenvolvida um projeto sobre desenho de cargos. Discute ainda sobre os modelos de avaliação da qualidade de vida no trabalho, e cita os mais importantes que são os modelos de QVT de Nadler e Lawler, o modelo de Hackman e Oldhan e o modelo de QVT de Walton.

Para Souza et al. (2013), dada a expansão dos estudos acerca da qualidade de vida no trabalho, percebe-se que existem uma variedade de teorias e modelos, sendo que merece destaque: O Modelo de Walton (1973) que propõe um modelo de avaliação da QVT a partir de oito fatores básicos: 1. Compensação justa e adequada; 2 . Segurança e saúde nas condições de trabalho; 3 . Oportunidade imediata para utilização e desenvolvimento das capacidades humanas; 4 . Oportunidade futura para crescimento contínuo e garantia profissional; 5. Integração social na organização; 6. Constitucionalismo; 7. Trabalho e espaço total da vida; 8. Relevância social do trabalho. O Modelo de Westley (1979) estuda a qualidade de vida no trabalho de uma perspectiva mais ampla, analisando-a a partir de quatro diferentes problemas (econômico, político, psicológico e sociológico), sugerindo algumas soluções a partir de práticas organizacionais que estimulem a cooperação, a divisão de lucros, a supervisão do trabalho, o enriquecimento das tarefas e a formação de 
grupos de trabalho estruturados. E o Modelo de Hackman et al. (1975), por sua vez, sugerem uma nova estratégia de redesenho dos postos de trabalho, tendo em vista a melhoria.

Chiavenato (2014) comenta que o modelo de Nadler et al. está fundamentado em quatro aspectos: participação dos funcionários, reestruturação do trabalho, inovação no sistema de recompensas, melhora no ambiente de trabalho. Vasconcelos et al. (2009) enfatizam que a saúde, a higiene e a segurança do trabalho são fatores vitais na prevenção de acidentes e na defesa da saúde do empregado, evitando o sofrimento humano e o desperdício econômico lesivo às empresas e ao próprio País.

\section{Higiene no Trabalho}

Higiene no trabalho, na visão de Chiavenato (2014), envolve as condições ambientais do trabalho que asseguram a saúde física e mental das pessoas, e com as condições de bem-estar delas. A saúde física, o trabalho na área de ação da higiene no trabalho, os aspectos ligados do organismo humano, também nos agentes externos, o ar, temperatura, umidade. A saúde mental, o trabalho envolve as condições psicológicas e sociológicas evitando os impactos, como o estresse.

Ferreira et al. (2017) corroboram dizendo que a higiene do trabalho está ligada diretamente com a fonte para alcançar o sucesso de uma empresa através da alta produtividade, ela conserva a saúde dos colaboradores e a prevenção de acidentes, através de programas e treinamentos, educando-os e alertandoos dos perigos e riscos existentes no local de trabalho, reduzindo os efeitos prejudiciais. Já para Mendes et al. (2001), o sofrimento no trabalho se manifesta pela insatisfação em relação ao conteúdo significativo da tarefa e pela insatisfação frente ao seu conteúdo ergonômico. A insatisfação em relação ao conteúdo significativo da tarefa ocorre quando o trabalhador não identifica um sentido na sua execução seja para a própria organização, para a sociedade ou até mesmo para sua família. A insatisfação frente ao conteúdo ergonômico da tarefa refere-se ao ambiente de trabalho físico - luminosidade, temperatura, ruídos, às condições de higiene, de segurança e, às características antropométricas nos postos de trabalho.

Ferreira et al. (2017) enfatizam que o trabalho das pessoas é pautado nas condições ambientais, de tempo, sociais, e que os principais fatores a serem cuidadosamente analisados de são os ambientes físicos e psicológicos. Os fatores físicos serão observados nos seguintes aspectos, adequação a luz, a ventilação, a temperatura, o ruído, umidade, substancias toxicas, e aos equipamentos de segurança. Os fatores psicológicos são de maiores relevâncias, sendo importante o relacionamento com os colegas de trabalho, a motivação e a diminuição do estresse.

O estresse vem sendo considerado um dos problemas mais conceituados, que afetam todos os trabalhadores ou intensamente a organização junto da sociedade. Stefano et al. (2015) ponderam que o estresse surge como consequência refletida e advinda de extremos referentes à percepção do indivíduo sobre as pressões exercidas sobre este, e a habilidade de trabalhar no núcleo dessa pressão de modo que esta não interfira na sua qualidade de vida.

Segundo Chiavenato (2014), no contexto de custos, pode-se destacar para as empresas, relacionados aos distúrbios de estresse dos funcionários, a relação desagradável entre funcionários afetando toda a 
empresa, e os relacionamentos profissionais, o colaborador, além disso, não deixa sua fadiga ali mesmo no trabalho acaba levando para sua própria residência, afetando seus relacionamentos pessoais também.

Stefano et al. (2015) inferem que estresse não é uma doença, quando se apresenta em determinada intensidade é apenas um estímulo gerado no organismo para reagir mediante determinada situação, sendo que cada indivíduo tem uma característica própria de reação conforme cada situação que este enfrenta no dia a dia, seja no trabalho, na vida acadêmica, porém esse estado pode acarretar alterações que o indivíduo não tem controle.

Na visão de Chiavenato (2009) um plano de higiene do trabalho geralmente envolve os seguintes conteúdos: plano organizado, envolvendo a prestação de serviços médicos, de enfermeiros e auxiliares, em tempo integral ou parcial, dependendo do tamanho da empresa; serviços médicos adequados; eliminação de áreas insalubres; exames médicos periódicos de revisão; serviços adicionais, como investimentos empresariais sobre a saúde do empregado e da comunidade, programas informativos para melhorar a qualidade de vida, extensão de benefícios médicos a empregados aposentados, incluindo planos de pensão ou de aposentadoria, dentre outros. Neste contexto, as organizações necessitam de um planejamento adequado e cauteloso sobre a higiene do trabalho a fim de conseguir melhores condições de vida para as pessoas envolvidas.

\section{Segurança no Trabalho}

Para Chiavenato (2014) segurança do trabalho é o conjunto de medidas de ordem técnica, educacional, médica e psicológica são utilizadas para prevenir acidentes, eliminando as condições inseguras do ambiente. Já Fidelis et al. (2007) enfatizam que segurança no trabalho é o conjunto de medidas que tem por meio objetivo a prevenção e a eliminação de causas de acidentes no trabalho.

Chiavenato (2014) relata que a segurança no trabalho envolve três divisões de prevenção de acidentes são elas: prevenção de acidentes, prevenção de incêndios e prevenção de roubos. A prevenção de acidentes relaciona o cuidado sobre a lesão e doenças relacionados no colaborador tomando cuidados para que não ocorram acidentes.

Carvalho (2013) comenta que a Comissão Interna de Prevenção de Acidentes/CIPA é de grande importância para todos os envolvidos na organização, tem por finalidade a prevenção de acidentes, utilizando como mecanismos os treinamentos, uso correto dos Equipamentos de Proteção Individual, auxilio no combate a incêndios, dentre outras funções.

Tavares (2009) enfatiza que os Equipamentos de Proteção Individual/EPI é o equipamento pessoal do trabalhador que serve para a protegê-lo dos riscos aos quais estão expostos, dessa forma, cada atividade laboral requer o uso especifico de determinados equipamentos. Para Cisz (2015) atualmente, as normas regulamentadoras, relativas à segurança e medicina do trabalho, já são trinta e seis (36), visto a necessidade nos diversos ambientes de trabalho. Destaque para a Norma Regulamentadora (NR-6), que trata dos equipamentos de proteção individual, aprovada em 8 de junho de 1978, mesma já passou por diversas alterações. 
Na visão de Tavares (2009) a recomendação do EPI adequado ao risco, ao empregador, é de competência do Serviço Especializado em Engenharia de Segurança e em Medicina do Trabalho (SESMT), quando as empresas estiverem desobrigadas a manter o SESMT. Ainda, nas empresas desobrigadas de constituir CIPA, cabe ao designado, mediante orientação de profissional tecnicamente habilitado, recomendar o EPI adequado à proteção do trabalhador. Cisz (2015) enfatiza que de acordo com a Norma Regulamentadora, NR-6, define-se Equipamento de Proteção Individual como todo dispositivo ou produto de uso individual utilizado pelo trabalhador com o intuito de proteção aos riscos sujeitos de ameaça a segurança e a saúde no trabalho.

De acordo com a NR 6, do Ministério do Trabalho e Emprego, os equipamentos de proteção individual são divididos em: EPI para proteção da cabeça: a) Capacete: proteção do crânio contra impactos, choques elétricos e no combate a incêndios; b) Capuz: proteção do crânio contra riscos de origem térmica, respingos de produtos Químicos e contato com partes móveis de máquinas. EPI para proteção dos olhos e face: a) Óculos: proteção dos olhos contra impactos de partículas volantes, luminosidade intensa, radiação ultravioleta, radiação infravermelha e contra respingos de produtos químicos; b) Protetor facial: proteção da face contra impactos de partículas volantes, respingos de produtos químicos, radiação infravermelha e luminosidade intensa; c) Máscara de solda: proteção dos olhos e face contra impactos de partículas volantes, radiação ultravioleta, radiação infravermelha e luminosidade intensa. EPI para proteção respiratória: a) Respirador purificador de ar: para proteção das vias respiratórias contra poeiras e névoas, poeiras, névoas e fumos, poeiras, névoas, fumos e radionuclídeos, vapores orgânicos ou gases ácidos em ambientes com concentração inferior a 50 ppm (parte por milhão), partículas e gases emanados de produtos químicos e respirador purificador de ar motorizado para proteção das vias respiratórias contra poeiras, névoas, fumos e radionuclídeos; b) Respirador de adução de ar: tipo linha de ar comprimido e tipo máscara autônoma de circuito aberto ou fechado para proteção das vias respiratórias em atmosferas com concentração Imediatamente Perigosa à Vida e à Saúde (IPVS) e em ambientes confinados; c) Respirador de fuga: respirador de fuga para proteção das vias respiratórias contra agentes químicos em condições de escape de atmosferas imediatamente perigosa à vida e à saúde (IPVS) ou com concentração de oxigênio menor que 18 \% em volume.

A NR 6, descreve ainda sobre o EPI para proteção do tronco: a) Vestimentas de segurança que ofereçam proteção ao tronco contra riscos de origem térmica, mecânica, química, radioativa e meteorológica e umidade proveniente de operações com uso de água; b) Colete à prova de balas de uso permitido para vigilantes que trabalhem portando arma de fogo, para proteção do tronco contra riscos de origem mecânica. EPI para proteção dos membros superiores: luvas, creme protetor, manga de segurança para os braços, braçadeira e dedeira. EPI para proteção dos membros inferiores: Calçados de segurança, meia de segurança, perneiras, calça. EPI para proteção do corpo inteiro: macacão, conjunto, e vestimenta de corpo inteiro. EPI para proteção contra quedas com diferentes níveis: Dispositivo trava-queda e cinturão, dentre outros.

Segundo Cisz (2015), apesar de existir inúmeros riscos vinculados ao ambiente de trabalho, a falta de utilização dos EPIs continua sendo um dos principais fatores que causam maior gravidade aos acidentes de 
trabalho.

\section{METODOLOGIA}

$\mathrm{Na}$ construção deste estudo foi utilizado às técnicas de bibliometria que possibilita o mapeamento de pesquisa, explorando o acervo de periódicos da Associação Nacional de Pós-Graduação e Pesquisa em Administração/ANPAD, exclusivamente no Encontro de Gestão de Pessoas e Relações de Trabalho/EnGPR. O EnGPR é realizado sob promoção da Associação Nacional de Pós-Graduação e Pesquisa em Administração/ANPAD e de responsabilidade da Divisão Acadêmica de Gestão de Pessoas e Relações de Trabalho/GPR. O EnGPR é um espaço de discussão de temas relevantes de Gestão de Pessoas e Relação de Trabalhos, por isso, o objetivo geral do evento é promover a interlocução entre estudiosos dessa área e, nessa medida, auxiliar no desenvolvimento da área no Brasil, observando, preferencialmente, os Temas de Interesse destacados, por meio de artigos teórico-empíricos, ensaios teóricos e artigos tecnológicos. Este evento subdivide em vários temas de interesse: Trabalho e diversidade; gestão de carreiras; mudanças e permanência nas relações de trabalho; liderança e desenvolvimento gerencial; prazer e sofrimento no trabalho; trabalho, gestão e subjetividade; políticas modelos e práticas em gestão de pessoas; conhecimento e aprendizagem; competências; gestão de pessoas, relações de trabalho e comportamento organizacional (ANPAD, 2016).

$\mathrm{Na}$ visão de Ferreira et al. (2015) a bibliometria trata-se de técnicas quantitativas de analisar produções científicas, analisam-se o conteúdo, envolvendo títulos, palavras-chave, resumos, textos, autores, instituições, métodos, envolvendo autoria e referências bibliográficas, observando as principais características gerais das publicações: ano de publicação, evento ou periódicos, principais autores, número de autores por artigo, instituições, e também aspectos metodológicos das publicações: Quanto aos objetivos da pesquisa, natureza, abordagem, procedimentos, instrumentos utilizados para a coleta de dados, dentre outros.

A classificação desta pesquisa trata-se de uma pesquisa descritiva, quanto à abordagem quantitativa, e relacionada aos procedimentos é uma pesquisa bibliográfica, utilizando o método de bibliometria. A coleta de dados abrangeu amostras relevantes relacionadas ao tema de estudo, selecionados e apresentados nos periódicos ANPAD, nos eventos do EnGPR. A escolha destes eventos como base de pesquisa é devido à importância e relevância nos campos de pesquisa, já descritos anteriormente. Delimitou-se como unidades de analise os periódicos já citados, no EnGPR da ANPAD, no período de 2007 a 2016, todos os assuntos relacionados ao tema qualidade de vida no trabalho, foram levantadas as produções acadêmicas a serem analisadas, sendo que deste universo foram extraídas vinte (20) publicações no total, considerando aspectos de maior relevância para o assunto proposto.

Para a análise dos dados foi montado um banco de dados no Microsoft Office Excel 2013, contendo as seguintes características de todas as publicações: ano de publicação, título, nome dos autores, objetivos da pesquisa, metodologia, considerações e/ou conclusões, em sequência os dados coletados foram tratados 
através de fórmulas estatísticas, a fim de detectar o percentual necessário de cada item analisado, servindo de suporte para identificar os resultados esperados e auxiliar nas conclusões finais.

\section{RESULTADOS E DISCUSSÃO}

\section{Dentre os principais estudos organizacionais, no EnGPR da ANPAD com ênfase na Qualidade de}

Vida do Trabalho, entre o período de 2007 a 2016, foram selecionados vinte (20) publicações no total, que servirão de base de dados para análise e contribuições para os resultados e conclusão. O Quadro 1

apresenta as pesquisas com ênfase na Qualidade de Vida do Trabalho, abordando os autores, objetivo

geral, metodologia e as considerações/conclusões.

Quadro 1: Pesquisas com ênfase na qualidade de vida no trabalho, no EnGPR, no período de 2007 - 2016.

\begin{tabular}{|c|c|c|c|}
\hline AUTOR (ES) & OBJETIVOS & METODOLOGIA & CONSIDERAÇÕES/CONCLUSÃO \\
\hline $\begin{array}{l}\text { Oliva et al. } \\
\text { (2007) }\end{array}$ & $\begin{array}{l}\text { Identificar a satisfação } \\
\text { percebida pelos Comissários } \\
\text { de Bordo no Brasil com } \\
\text { relação à qualidade de vida } \\
\text { no trabalho. }\end{array}$ & $\begin{array}{l}\text { Pesquisa exploratória, quantitativa, } \\
\text { estudo de caso, utilizando como } \\
\text { instrumento na coleta de dados o } \\
\text { questionário e entrevista. }\end{array}$ & $\begin{array}{l}\text { Os entrevistados foram positivos em suas respostas e } \\
\text { que, apesar da crise que a indústria da aviação vem } \\
\text { enfrentando, os profissionais sentem orgulho da } \\
\text { empresa em que trabalham. No geral, os profissionais } \\
\text { mais jovens e com até um ano de empresa estão mais } \\
\text { satisfeitos. O resultado mais importante desta } \\
\text { pesquisa é que a remuneração é um fator } \\
\text { imprescindível para estes profissionais. }\end{array}$ \\
\hline $\begin{array}{l}\text { Paiva et al. } \\
\text { (2007) }\end{array}$ & $\begin{array}{l}\text { Descrever e analisar o corpo } \\
\text { gerencial de uma empresa } \\
\text { pública no que diz respeito às } \\
\text { variáveis de qualidade de } \\
\text { vida no trabalho e de estresse } \\
\text { ocupacional. }\end{array}$ & $\begin{array}{l}\text { Pesquisa descritiva, de enfoque } \\
\text { quantitativo e qualitativo, pesquisa } \\
\text { de campo; e a coleta de dados foi } \\
\text { através de questionário. }\end{array}$ & $\begin{array}{l}\text { De uma maneira geral, a qualidade de vida dos } \\
\text { pesquisados apresenta-se com níveis satisfatórios. A } \\
\text { partir de uma análise conjunta dos resultados, aponta- } \\
\text { se para uma realidade de estresse. Assim, a } \\
\text { estruturação de políticas e práticas de gestão de } \\
\text { pessoas mais abrangentes é necessária para a } \\
\text { identificação, a desmistificação o omonitoramento do } \\
\text { estresse ocupacional entre os gerentes da empresa, } \\
\text { passando por pesquisas mais específicas de } \\
\text { diagnóstico. }\end{array}$ \\
\hline $\begin{array}{l}\text { Schirmneister } \\
\text { et al. (2007) }\end{array}$ & $\begin{array}{l}\text { A proposta deste estudo foi } \\
\text { investigar } \\
\text { como são as relações da } \\
\text { qualidade de vida no trabalho } \\
\text { em equipes com múltiplas } \\
\text { formas de contratação. }\end{array}$ & $\begin{array}{l}\text { Estudo exploratório, descritivo e } \\
\text { transversal único; estudo de caso; e a } \\
\text { coleta de dados foi através de } \\
\text { questionário. }\end{array}$ & $\begin{array}{l}\text { Conclui-se que provavelmente o tipo de contrato } \\
\text { interfere na percepção de QVT dos colaboradores. }\end{array}$ \\
\hline $\begin{array}{l}\text { Cabral et al. } \\
(2009)\end{array}$ & $\begin{array}{l}\text { Apresentar a descrição e } \\
\text { análise das principais fontes } \\
\text { de satisfação, de insatisfação } \\
\text { e de pressão presentes no } \\
\text { trabalho de chefes e } \\
\text { auxiliares de cozinha que } \\
\text { atuam em restaurantes } \\
\text { localizados na cidade de Belo } \\
\text { Horizonte. }\end{array}$ & $\begin{array}{l}\text { Pesquisa descritiva, de caráter } \\
\text { quantitativo e } \\
\text { qualitativo; pesquisa de campo; e a } \\
\text { coleta de dados foi através de } \\
\text { questionário e entrevistas. }\end{array}$ & $\begin{array}{l}\text { Os resultados mais expressivos do estudo, } \\
\text { comparando-se os cargos de chefes e auxiliares de } \\
\text { cozinha, demonstram opiniões semelhantes quanto à } \\
\text { identidade da tarefa e o feedback extrínseco. Mas, nas } \\
\text { dimensões variedade de habilidades; significado da } \\
\text { tarefa; autonomia; feedback intrínseco e inter- } \\
\text { relacionamento, as opiniões dos chefes de cozinha } \\
\text { enaltecem a profissão, referindo-se a gostar do que } \\
\text { fazem, satisfação do ego, escolha certa de profissão e } \\
\text { trabalho duro, mas gratificante. }\end{array}$ \\
\hline $\begin{array}{l}\text { Pazini et al. } \\
\text { (2009) }\end{array}$ & $\begin{array}{l}\text { Identificar os níveis de } \\
\text { satisfação da qualidade de } \\
\text { vida no trabalho dos } \\
\text { funcionários das empresas do } \\
\text { sistema "S", do município de } \\
\text { Guarapuava, Estado do } \\
\text { Paraná. }\end{array}$ & $\begin{array}{l}\text { O estudo constitui-se do } \\
\text { embasamento teórico e da pesquisa } \\
\text { de campo exploratória e quantitativa; } \\
\text { e a coleta de dados foi através de } \\
\text { questionário. }\end{array}$ & $\begin{array}{l}\text { Os resultados obtidos demonstram índices de } \\
\text { satisfação em algumas variáveis de QVT, como a } \\
\text { imagem da empresa, oportunidade de treinamento e } \\
\text { aperfeiçoamento; em contrapartida, há alguns índices } \\
\text { de insatisfação com a qualidade dos programas de } \\
\text { prevenção de doenças; oportunidade para lazer e } \\
\text { entretenimento e controle dos riscos ergonômicos e } \\
\text { ambientais. }\end{array}$ \\
\hline $\begin{array}{l}\text { Bonanato et } \\
\text { al. (2009) }\end{array}$ & $\begin{array}{l}\text { Identificar os fatores de } \\
\text { estresse no ambiente de } \\
\text { trabalho que podem ser } \\
\text { causados pela natureza do } \\
\text { mesmo e suas condições, a } \\
\text { Conflitos interpessoais entre } \\
\text { o trabalho e as obrigações } \\
\text { pessoais e às necessidades } \\
\text { pessoais de auto realização } \\
\text { em uma Universidade Pública } \\
\text { do Estado do Paraná. }\end{array}$ & $\begin{array}{l}\text { A pesquisa em questão caracteriza-se } \\
\text { como sendo exploratório, com } \\
\text { procedimentos de } \\
\text { interrogação/comunicação por meio } \\
\text { de questionário. Adicionalmente, } \\
\text { trata-se de um estudo ex post facto, } \\
\text { transversal e em condições de } \\
\text { campo. }\end{array}$ & $\begin{array}{l}\text { Os resultados demonstraram que tanto homens } \\
\text { quanto mulheres possuem taxas de estresse acima do } \\
\text { recomendado, com variações específicas. As mulheres } \\
\text { pesquisadas, obtiveram maior incidência de } \\
\text { problemas físicos relacionados ao estresse que os } \\
\text { homens. A atividade física revelou-se uma importante } \\
\text { forma da organização diminuir, ou até evitar o } \\
\text { estresse entre seus funcionários, implementando } \\
\text { programas dentro do próprio ambiente. }\end{array}$ \\
\hline
\end{tabular}




\begin{tabular}{|c|c|c|c|}
\hline $\begin{array}{l}\text { Vasconcelos } \\
\text { et al. (2009) }\end{array}$ & $\begin{array}{l}\text { Identificar os fatores que } \\
\text { causam o } \quad \text { Estresse } \\
\text { Ocupacional na atividade dos } \\
\text { motoristas de Transporte } \\
\text { Urbano da Cidade do Rio de } \\
\text { Janeiro. }\end{array}$ & $\begin{array}{l}\text { Pesquisa de campo e estudo de caso. } \\
\text { A elaboração do estudo de caso foi } \\
\text { baseada em coleta de dados } \\
\text { quantitativa e qualitativa. Os dados } \\
\text { foram obtidos por meio de um } \\
\text { questionário, } \\
\text { e de entrevistas complementares } \\
\text { semiestruturadas. }\end{array}$ & $\begin{array}{l}\text { A pesquisa apontou a necessidade de melhorar a } \\
\text { gestão das empresas de transporte público, pois seus } \\
\text { motoristas apresentam problemas físicos e nível de } \\
\text { estresse considerável, devido às condições de } \\
\text { trabalho. Apesar das condições de trabalho } \\
\text { insatisfatórias, observou-se que os motoristas } \\
\text { apresentam um alto grau de satisfação com seu } \\
\text { trabalho. O desgaste emocional é o sintoma mais } \\
\text { expressivo, sendo necessária uma melhoria da } \\
\text { qualidade de vida dos trabalhadores que atuam nesta } \\
\text { atividade. }\end{array}$ \\
\hline $\begin{array}{l}\text { Simoni et al. } \\
(2009)\end{array}$ & $\begin{array}{l}\text { Analisar a satisfação no } \\
\text { trabalho das enfermeiras que } \\
\text { atuam em organização } \\
\text { hospitalar, caracterizando a } \\
\text { organização hospitalar e o } \\
\text { trabalho das enfermeiras, } \\
\text { relacionando os com a } \\
\text { satisfação no trabalho, e, } \\
\text { identificando os fatores de } \\
\text { satisfação das enfermeiras no } \\
\text { trabalho. }\end{array}$ & $\begin{array}{l}\text { Pesquisa descritiva, quantitativa, e } \\
\text { estudo de caso; a coleta de dados foi } \\
\text { através de questionário. }\end{array}$ & $\begin{array}{l}\text { Como resultados encontrados, destacam-se: as } \\
\text { enfermeiras reconhecem como fator importante, para } \\
\text { a sua satisfação no trabalho o apoio instrumental } \\
\text { recebido para o desenvolvimento de suas atividades, } \\
\text { proveniente das chefias e das colegas, sendo este } \\
\text { prioritário em relação às interações sociais } \\
\text { estabelecidas; as enfermeiras encontram-se mais } \\
\text { satisfeitas com suas chefias do que com suas colegas; } \\
\text { as enfermeiras identificam-se fortemente com a sua } \\
\text { profissão, o que influencia positivamente na sua } \\
\text { satisfação com o trabalho; o reconhecimento } \\
\text { profissional é um fator de forte correlação com a } \\
\text { satisfação no trabalho, assim como são importantes a } \\
\text { participação e a promoção de atividades educacionais; } \\
\text { os fatores relacionados a promoção e salário } \\
\text { representam os aspectos com menores médias de } \\
\text { satisfação. }\end{array}$ \\
\hline $\begin{array}{l}\text { Silva et al. } \\
(2009)\end{array}$ & $\begin{array}{l}\text { Objetiva compreender as } \\
\text { relações de trabalho no } \\
\text { âmbito das Organizações Não } \\
\text { Governamentais (ONG's) e } \\
\text { como as tendências recentes } \\
\text { de flexibilização do trabalho } \\
\text { afetam seus trabalhadores. }\end{array}$ & $\begin{array}{l}\text { Levantamento bibliográfico; estudo } \\
\text { de caso; a coleta de dados foi através } \\
\text { de entrevistas. }\end{array}$ & $\begin{array}{l}\text { Pode-se argumentar que os trabalhadores nessas } \\
\text { organizações também sofrem as tendências de } \\
\text { flexibilização e precarização dos direitos do trabalho, } \\
\text { sobretudo, em terrenos como os dos salários e das } \\
\text { jornadas de trabalho. Pautadas por um modelo mais } \\
\text { amplo que avilta e suprime direitos, as ONG's atuam, } \\
\text { no campo das relações de trabalho, sob uma lógica } \\
\text { que contraria muitos dos seus princípios e finalidades, } \\
\text { como a defesa de direitos. }\end{array}$ \\
\hline $\begin{array}{l}\text { Leite Júnior et } \\
\text { al. (2009) }\end{array}$ & $\begin{array}{l}\text { Investigar como se manifesta } \\
\text { o estresse em funcionários } \\
\text { públicos de um Instituto de } \\
\text { Pesquisas, quais as } \\
\text { estratégias de } \\
\text { enfrentamento adotadas } \\
\text { pelos mesmos e comparar os } \\
\text { dados levantados com a } \\
\text { média da população } \\
\text { brasileira. }\end{array}$ & $\begin{array}{l}\text { Pesquisa exploratória, descritiva, } \\
\text { com abordagem de natureza } \\
\text { quantitativa; pesquisa de campo; a } \\
\text { coleta de dados foi através de } \\
\text { questionário. }\end{array}$ & $\begin{array}{l}\text { Nota-se que um número significativo de sujeitos } \\
\text { apresenta estresse físico, psicológico, psico-fisiológico } \\
\text { e de temporalidade, já apresentando sintomas em } \\
\text { cada uma dessas modalidades. Além disto, se utilizam } \\
\text { de estratégias de enfrentamento ligadas à fuga e à } \\
\text { negação dos problemas, o que indica uma gestão } \\
\text { deficiente do estresse. }\end{array}$ \\
\hline $\begin{array}{l}\text { Cavedon } \\
(2011)\end{array}$ & $\begin{array}{l}\text { Identificar como a qualidade } \\
\text { de vida no trabalho é afetada } \\
\text { em decorrência das } \\
\text { percepções olfativas e quais } \\
\text { as implicações na saúde dos } \\
\text { servidores que integram o } \\
\text { Departamento de } \\
\text { Criminalística vinculado ao } \\
\text { Instituto-Geral de Perícias do } \\
\text { Rio } \\
\text { Grande do Sul. }\end{array}$ & $\begin{array}{l}\text { A opção metodológica para a } \\
\text { realização da pesquisa recaiu sobre a } \\
\text { etnografia. }\end{array}$ & $\begin{array}{l}\text { Os dados revelaram que o 'cheiro da morte' é tido } \\
\text { como algo difícil de ser suportado pelos servidores, o } \\
\text { cigarro serve para amenizar os odores pútridos e a } \\
\text { ingestão de certos alimentos pode ficar } \\
\text { comprometida pelo cheiro e visão do local de crime. }\end{array}$ \\
\hline $\begin{array}{l}\text { Abreu et al. } \\
(2011)\end{array}$ & $\begin{array}{l}\text { Visa a analisar a influência do } \\
\text { trabalho no turno noturno na } \\
\text { qualidade de vida } \\
\text { profissional e pessoal dos } \\
\text { trabalhadores em bares, } \\
\text { restaurantes e hotéis da } \\
\text { cidade de Maceió/AL. }\end{array}$ & $\begin{array}{l}\text { Pesquisa descritiva e exploratória; } \\
\text { pesquisa de campo; a coleta de } \\
\text { dados foi através de questionário. }\end{array}$ & $\begin{array}{l}\text { Pode-se concluir que, com base nos achados e na } \\
\text { revisão apresentada, os fatores de qualidade de vida } \\
\text { têm implicações na vida do trabalhador do turno } \\
\text { noturno nas empresas pesquisadas na cidade de } \\
\text { Maceió, identificando, também, aceitação de suas } \\
\text { atribuições e possibilidades em razão crescimento e } \\
\text { companheirismo entre partes pesquisadas, como, por } \\
\text { exemplo, como o ambiente de trabalho por influenciar } \\
\text { de forma positiva ou negativa, devendo os gestores } \\
\text { ficarem atentos a estes anseios dos colaboradores. }\end{array}$ \\
\hline $\begin{array}{l}\text { Souza et al. } \\
(2013)\end{array}$ & $\begin{array}{l}\text { Este artigo propõe a } \\
\text { avaliação do nível de } \\
\text { qualidade de vida no trabalho } \\
\text { (QVT) de servidores de um } \\
\text { órgão da administração } \\
\text { direta do Estado de Minas } \\
\text { Gerais. }\end{array}$ & $\begin{array}{l}\text { A pesquisa realizada é de natureza } \\
\text { descritiva, estudo de caso, } \\
\text { quantitativa, documental e } \\
\text { questionário online. }\end{array}$ & $\begin{array}{l}\text { Dos resultados obtidos depreende-se que, de modo } \\
\text { geral, os servidores pesquisados encontram-se } \\
\text { satisfeitos com as tarefas que executam junto ao } \\
\text { órgão, apresentando níveis de qualidade de vida } \\
\text { adequados. }\end{array}$ \\
\hline
\end{tabular}




\begin{tabular}{|c|c|c|c|}
\hline $\begin{array}{l}\text { Meyer et al. } \\
(2013)\end{array}$ & $\begin{array}{l}\text { Abordar a percepção dos } \\
\text { funcionários de uma agência } \\
\text { bancária acerca das vivências } \\
\text { de prazer-sofrimento no } \\
\text { trabalho. }\end{array}$ & $\begin{array}{l}\text { O método de pesquisa utilizado foi o } \\
\text { estudo de caso e os dados, coletados } \\
\text { por meio de entrevistas } \\
\text { semiestruturadas, foram } \\
\text { interpretados com a } \\
\text { utilização da ferramenta de análise } \\
\text { do conteúdo. }\end{array}$ & $\begin{array}{l}\text { Destaca-se que a maior parte das respostas em } \\
\text { relação às razões que motivam os funcionários a } \\
\text { continuarem exercendo seu trabalho não foram } \\
\text { fatores relacionados à realização pessoal e } \\
\text { profissional. A relativa estabilidade e os benefícios } \\
\text { oferecidos pela organização foram os fatores } \\
\text { considerados mais importantes e de grande incentivo } \\
\text { para os indivíduos tolerarem o serviço e relevarem } \\
\text { certas condições de trabalho. }\end{array}$ \\
\hline $\begin{array}{l}\text { Bcheche et al. } \\
\text { (2013) }\end{array}$ & $\begin{array}{l}\text { Buscou-se desenvolver e } \\
\text { validar escala para } \\
\text { mensuração do bem-estar no } \\
\text { trabalho de natureza } \\
\text { administrativa e gerencial, } \\
\text { por meio de abordagem } \\
\text { integradora entre os } \\
\text { conceitos de QVT, ergonomia } \\
\text { e estresse ocupacional. }\end{array}$ & $\begin{array}{l}\text { Esta pesquisa é de natureza } \\
\text { quantitativa e descritiva; e pesquisa } \\
\text { com survey. }\end{array}$ & $\begin{array}{l}\text { A constatação de que o fator 'Postura e disposição do } \\
\text { espaço físico' tem um impacto considerável no } \\
\text { aparecimento de sintomas de dor e desconforto no } \\
\text { pescoço, na coluna e no ombro demonstra a } \\
\text { necessidade de as organizações atuarem de forma } \\
\text { proativa por meio da intervenção ergonômica precoce } \\
\text { nos postos de trabalho com o intuito de evitar o } \\
\text { aparecimento de sintomas físicos e promover o bem- } \\
\text { estar no trabalho. }\end{array}$ \\
\hline $\begin{array}{l}\text { Paixão et al. } \\
\text { (2013) }\end{array}$ & $\begin{array}{l}\text { Analisar a percepção dos } \\
\text { professores de graduação em } \\
\text { Administração e } \\
\text { Ciências Contábeis de } \\
\text { universidades públicas } \\
\text { brasileiras sobre a qualidade } \\
\text { de vida no trabalho } \\
\text { (QVT). }\end{array}$ & $\begin{array}{l}\text { Foi realizado um estudo descritivo } \\
\text { com perspectiva analítica, de } \\
\text { natureza quali-quantitativa; pesquisa } \\
\text { com survey. }\end{array}$ & $\begin{array}{l}\text { Através dos resultados verificou-se quais condições } \\
\text { favoráveis e quais são as principais dificuldades } \\
\text { enfrentadas pelos docentes para manutenção de sua } \\
\text { QVT. }\end{array}$ \\
\hline $\begin{array}{l}\text { Lemos et al. } \\
(2015)\end{array}$ & $\begin{array}{l}\text { Analisar quais os fatores } \\
\text { direcionadores da } \\
\text { Qualidade de Vida no } \\
\text { Trabalho (QVT), com base na } \\
\text { percepção de servidores de } \\
\text { uma } \\
\text { organização pública. }\end{array}$ & $\begin{array}{l}\text { Pesquisa do tipo survey realizado por } \\
\text { meio da utilização de um } \\
\text { questionário. }\end{array}$ & $\begin{array}{l}\text { Os resultados encontrados nesse estudo revelam } \\
\text { aspectos a serem considerados para a compreensão } \\
\text { do ambiente de trabalho de indivíduos no serviço } \\
\text { público, podendo estes serem estendidos para a área } \\
\text { privada. }\end{array}$ \\
\hline $\begin{array}{l}\text { Almeida et al. } \\
\text { (2015) }\end{array}$ & $\begin{array}{l}\text { Associar o nível de satisfação } \\
\text { no trabalho e o nível de } \\
\text { estresse ocupacional com os } \\
\text { dados pessoais e } \\
\text { ocupacionais dos policiais } \\
\text { militares do Estado do Rio } \\
\text { Grande do Sul. }\end{array}$ & $\begin{array}{l}\text { Pesquisa de natureza descritiva, de } \\
\text { abordagem } \\
\text { quantitativa do tipo survey. }\end{array}$ & $\begin{array}{l}\text { Em relação a satisfação no trabalho predominou o } \\
\text { nível médio ( } 79,38 \%) \text {. Assim como o estresse } \\
\text { ocupacional, a maioria ( } 72,39 \%) \text { apresentou nível } \\
\text { médio. As variáveis, tempo de atuação e faixa de } \\
\text { renda, }\end{array}$ \\
\hline $\begin{array}{l}\text { Oliveira et al. } \\
\text { (2015) }\end{array}$ & $\begin{array}{l}\text { Analisar o grau } \\
\text { de satisfação dos professores } \\
\text { da REDE EPT em relação à } \\
\text { Qualidade de Vida no } \\
\text { Trabalho }\end{array}$ & $\begin{array}{l}\text { Pesquisa de natureza descritiva, de } \\
\text { abordagem } \\
\text { quantitativa do tipo survey. }\end{array}$ & $\begin{array}{l}\text { Os achados deste trabalho demonstram a necessidade } \\
\text { de alinhamento quanto à } \\
\text { política de gestão de benefícios e apoio familiar e } \\
\text { comunitário no grupo pesquisado e revelam a } \\
\text { qualidade da relação ensino-aprendizado neste } \\
\text { cenário. }\end{array}$ \\
\hline $\begin{array}{l}\text { Stefano et al. } \\
(2015)\end{array}$ & $\begin{array}{l}\text { Avaliar os níveis de estresse } \\
\text { em alunos no último ano de } \\
\text { graduação nos cursos de } \\
\text { Administração e de Ciências } \\
\text { Contábeis de uma } \\
\text { universidade pública no } \\
\text { estado do Paraná - Brasil. }\end{array}$ & $\begin{array}{l}\text { Pesquisa de natureza descritiva, de } \\
\text { abordagem } \\
\text { quantitativa do tipo survey., }\end{array}$ & $\begin{array}{l}\text { O estudo concluiu que os homens apresentaram } \\
\text { maiores níveis de estresse, porém preferiu considerar } \\
\text { que ambos os sexos apresentaram níveis de estresse } \\
\text { sendo que foram sugeridas técnicas do mindfulness a } \\
\text { serem aplicadas junto às práticas pedagógicas que a } \\
\text { universidade desenvolve. }\end{array}$ \\
\hline
\end{tabular}

No aspecto sobre a qualidade de vida no trabalho, o assunto mais debatido foi relacionado a satisfação no trabalho, o estresse ocupacional, ou seja, a maioria dos estudos focaram na higiene no trabalho. Nota-se que a abordagem sobre segurança no trabalho, no EnGPR ficou em segundo plano, bem como, não foi encontrado trabalhos que abordassem sobre o uso de equipamentos de proteção individual, assunto este que merece maior atenção por parte tanto empresarial, como dos pesquisadores da referida área.

\section{Características Gerais das Publicações}

A seguir serão apresentadas as características relevantes das publicações estudadas: distribuição de artigos por ano de publicação, formação máxima dos autores por publicação, quantidade de autores por produção científica, e também aspectos metodológicos das publicações: quanto à natureza, aos objetivos da 
pesquisa, quanto à abordagem, quanto aos procedimentos, e os instrumentos utilizados para a coleta de dados.

Observa-se que nos estudos sobre qualidade de vida no trabalho, em especifico no EnGPR da ANPAD, as discussões estão focadas sobre a higiene do trabalho, principalmente relacionado ao estresse dos funcionários no ambiente de trabalho. Sendo discutido também sobre a satisfação e insatisfação dos colaboradores, no qual um dos aspectos chaves envolve a remuneração, sendo considerado um dos requisitos básicos na determinação da in(satisfação).

Tabela 1: Distribuição de artigos por ano.

\begin{tabular}{|l|l|l|l|}
\hline Ano & No de publicações no EnGPR & $\begin{array}{l}\text { No de publicações sobre os temas } \\
\text { QUALIDADE DE VIDA NO TRABALHO } \\
\text { Higiene no Trabalho }\end{array}$ \\
\hline 2007 & 120 & 3 & 0 \\
\hline 2009 & 113 & 7 & 0 \\
\hline 2011 & 116 & 2 & 0 \\
\hline 2013 & 92 & 4 & 0 \\
\hline 2015 & 140 & 4 & 0 \\
\hline Total & $\mathbf{5 8 1}$ & $\mathbf{2 0}$ & $\mathbf{0}$ \\
\hline
\end{tabular}

Evidencia-se a preocupação por parte dos gestores e pesquisadores em manter um ambiente harmonioso, no entanto, a questão de segurança do trabalho está em segundo plano, assim sendo, constatase com este trabalho que as pesquisas acadêmicas do EnGPR, no período de 2007 a 2016, não abordou em especifico sobre o tema segurança no trabalho, ou seja, o foco principal, da maioria dos trabalhos, era na higiene do trabalho.

É notório a elevada importância da segurança no trabalho, a preocupação com minimizar acidentes, usos de EPI's, a prevenção em si. Assim este trabalho pretende enfatizar que as organizações precisam atuar na prevenção, ter Comissão Interna de Prevenção de Acidentes/CIPA, contratar técnicos em segurança do trabalho, fatos estes que são diferencial competitivo das empresas.

Utilizando as palavras contidas nos títulos dos artigos pesquisadas, foi construída a figura 1 , nuvens de palavras. Para criar as nuvens de palavras foi utilizado o programa Microsoft World, ou seja, foi descrito todos os títulos dos artigos em questão, em seguida, selecionado, copiado e colado no site de criação online. Pesquisadores com interesse nesta ferramenta segue uma lista com quadro ferramentas on-line para a criação de 'nuvens de palavras': www.wordle.net, www.tagxedo.com, www.tagul.com, www.tagcrowd.com.

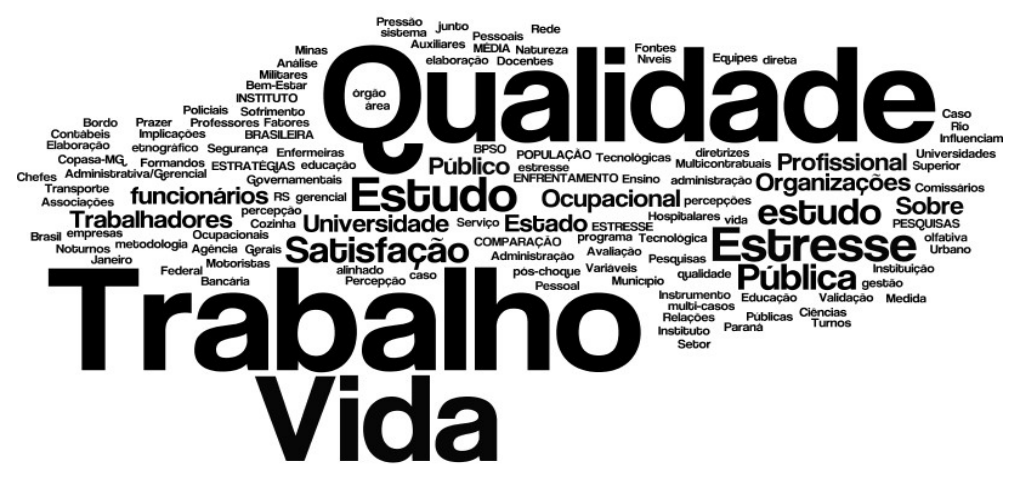

Figura 1: Frequências das palavras presentes nos títulos dos artigos. 
Percebe-se que as palavras: trabalho, qualidade, estresse, estudo percepção, pesquisas, administração, vida, satisfação, dentre outras foram as mais abordadas. Através da fundamentação teórica dos trabalhos analisados sobre o assunto foram feitas as redes de autores mais citados, conforme figura 2. De acordo com os trabalhos analisados, no período de 2007 a 2016, foi possível observar quais são os pesquisadores mais comentados pelos autores, com destaque Walton, Limongi-França, Hackman et al., Vasconcelos, entre outros pesquisadores que estudam ou estudaram sobre a qualidade de vida no trabalho.

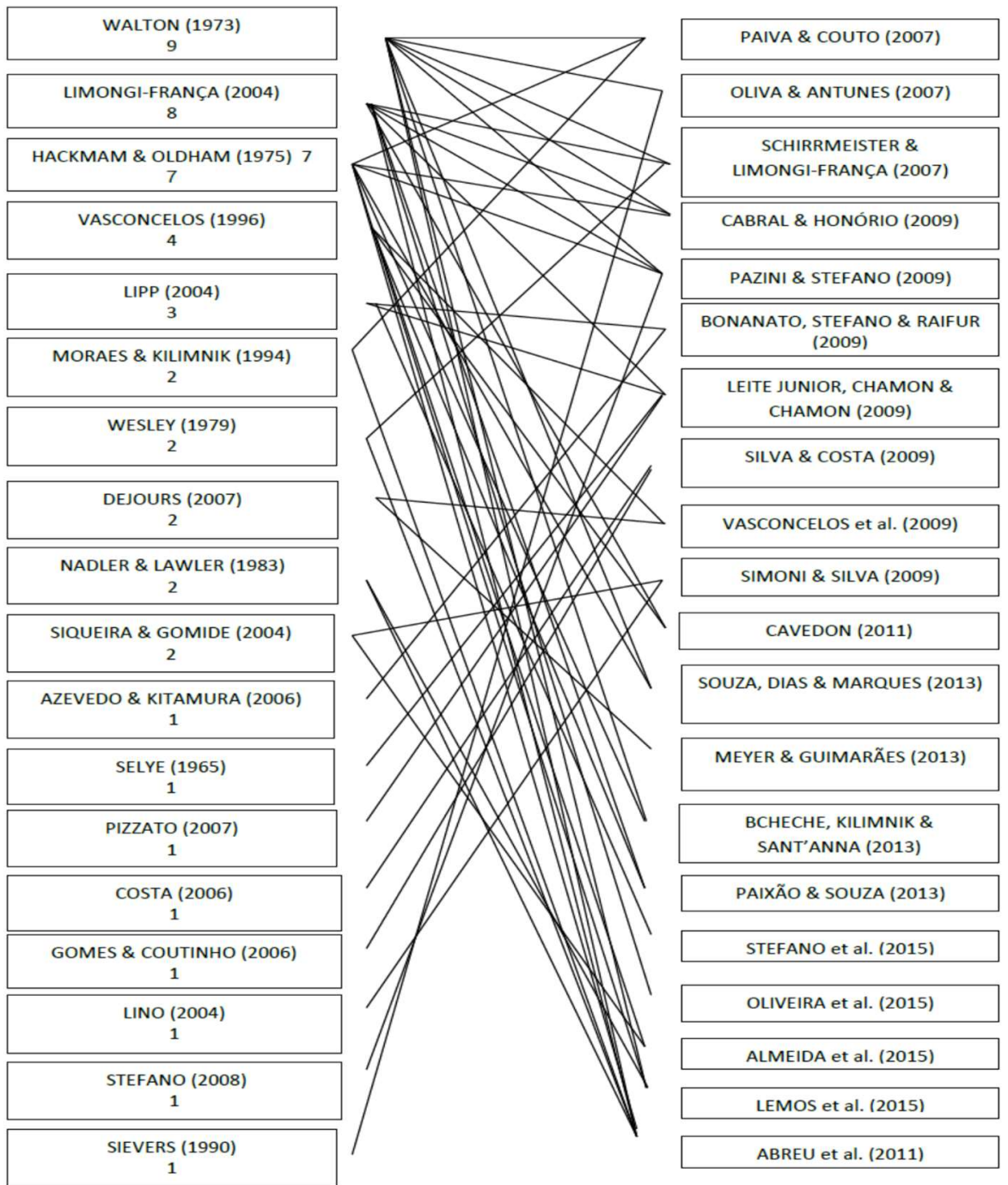

Figura 2: Autores mais citados nos trabalhos analisados.

\section{CONCLUSÕES}

Com base nos resultados, o assunto mais discutido foi relacionado à satisfação no trabalho, pois na maioria dos estudos da do EnGPR, no período de 2007 a 2016, o foco foi na higiene do trabalho, assim sendo, como o objetivo do trabalho foi de ampliar a discussão sobre a segurança no trabalho, percebe-se que neste quesito foi preciso buscar outras fontes de pesquisas sobre este assunto.

A segurança do trabalho é um dos pilares que contribuem para a satisfação do trabalhador no ambiente de trabalho e para minimizar custos e riscos para a empresa, assim é notório que a prevenção é algo de vital em qualquer organização. A adoção da Comissão Interna de Prevenção de Acidentes/CIPA não 
deve ser encarada como uma obrigação, ou apenas para seguir normas e regulamentos, mas, como um processo que contribui para o bem estar das pessoas envolvidas e o sucesso empresarial.

Além disso, a adoção de práticas preventivas como: o uso de equipamentos de proteção individualEPI; a organização e preocupação com o ambiente de trabalho; em resumo minimizar os fatores geradores de acidentes no trabalho, são fatores fundamentais. Peixoto (2011) enfatiza que os fatores geradores de acidentes no trabalho, podem ser relacionados ao arranjo físico (máquinas em posições inadequadas, materiais maldispostos, móveis sem boa conservação); ordem e limpeza precárias; máquinas e equipamentos sem proteção; ferramentas inadequadas e defeituosas; iluminação inadequada; eletricidade; algo com probabilidade de incêndio e explosão, como material inflamável e/ou explosivo; armazenamento inadequado; entre outros.

Além dos gestores urbanos, os empreendedores rurais devem ter a preocupação com a segurança no trabalho, pois, o agronegócio brasileiro é o motor de nosso país, e garantir a segurança, aos funcionários e demais envolvidos, é fundamental. Sabe-se que a rotina no campo exige cuidado, tanto em relação a execução das tarefas, como na prevenção no uso de agrotóxicos, ficou claro, da importância da segurança do trabalho, tanto para a empresa como para os colaboradores, favorece a qualidade de vida e bem estar dos funcionários e consequentemente impacta no aumento da produção, ou seja, funcionários satisfeitos com certeza produzirão mais, em contrapartida aumentam os ganhos do empreendimento. Foi possível compreender também que em uma revisão de literatura a técnica de bibliometria auxilia na compreensão dos estudos e pesquisas sobre o assunto.

\section{REFERÊNCIAS}

ABREU, N. R.; BALDANZA, R. F.; SERQUEIRA, I. F. G.; SILVA, R. A.. Trabalho em Turnos Noturnos: Implicações na Qualidade de Vida Profissional e Pessoal dos Trabalhadores. João Pessoa: EnGPR, 2011.

ALMEIDA, D. M.; LOPES, L. F. D.; COSTA, V. M. F.; SANTOS, R. C. T.; TOMAZZONI, G. C.. Satisfação no Trabalho e Estresse Ocupacional: Associações entre as Variáveis Pessoais e Ocupacionais de Policiais Militares do RS. Salvador: EnGPR, 2015.

ANDRADE, L. F. S.; MACEDO, A. S.; OLIVEIRA, M. L. S.. A produção científica em gênero no Brasil: um panorama dos grupos de pesquisa de administração. In: ENCONTRO DE ESTUDOS ORGANIZACIONAIS - ENEO. Anais. Gramado, 2014.

BCHECHE, I. C.; KILIMNIK, Z. M.; SANTANA, A. S.. Bem-Estar no Trabalho de Natureza Administrativa/Gerencial e Fatores que o Influenciam: Elaboração e Validação de Instrumento de Medida. Brasília: EnGPR, 2013.

BONANATO, F. M.; STEFANO, S. R.; RAIFUR, L.. Estresse em funcionários de uma Universidade Pública do Estado do Paraná. Curitiba: EnGPR, 2009.

CABRAL, J. C.; HONÓRIO, L. C.. Qualidade de Vida e Fontes de Pressão no Trabalho: um Estudo com Chefes e Auxiliares de Cozinha. Curitiba: EnGPR, 2009.
CARVALHO, A. V.. Administração de Recursos Humanos. 2 ed. São Paulo: Cengage Learning, 2013.

CAVEDON, N. R.. A percepção olfativa e a Qualidade de Vida no Trabalho: um estudo etnográfico na área da Segurança Pública. João Pessoa: EnGPR, 2011.

CHIAVENATO, I.. Gestão de pessoas: o novo papel dos recursos humanos nas organizações. 4 ed. São Paulo: Manole, 2014.

CISZ, C. R.. Conscientização do uso de EPI's quanto à segurança pessoal e coletiva. Especialização (Bacharelado em engenharia de segurança do trabalho) - Universidade Tecnológica Federal do Paraná, Curitiba, 2015.

FALCO, A.; CASTANHEIRA, R.. 0 processo de gestão de pessoas em empresas de comunicação. Campo Grande: Comunicação \& Mercado, 2012.

FERREIRA, J. B.; SADOYAMA, A. S. P.; CORREIA, A. F. C.; GOMES, P. A de T.. Diversidade e gênero no contexto organizacional. RPCA, Rio de Janeiro, v.9, n.3, p.45-66, 2015.

FIDELIS, G. J.; BANOV, M. R.. Gestão de Recursos Humanos. 2 ed. São Paulo: Érica, 2007. 
LEITE JUNIOR, J. A. P.; CHAMON, E. M. Q. O.; CHAMON, M. A.. Estresse e estratégias de enfrentamento em um instituto de pesquisa: Comparação com a média da população brasileira. Curitiba: EnGPR, 2009.

LEMOS, R. B.; KLEIN, L. L.; PEREIRA, B. A. D.; BELTRAME, G.; RAVANELLO, F. S.; ALVES, J. N.. Qualidade De Vida No Serviço Público: Uma Avaliação Em Uma Instituição de Ensino Superior. Salvador: EnGPR, 2015.

MEYER, A. M.; GUIMARÃES, L. V. M.. 'Mais Prazer ou Mais Sofrimento?': Um Estudo com Trabalhadores de uma Agência Bancária. Brasília: EnGPR, 2013.

OLIVA, E. C.; ANTUNES, A. R.. Um Estudo Sobre a Qualidade de Vida no Trabalho dos Comissários de Bordo no Brasil. Natal: EnGPR, 2007.

OLIVEIRA, R. R.; LIMONGI FRANÇA, A. C.; NOMELINI, Q. S. S.; CASTRO, D. S. P.; ALVES, L. R.. A Qualidade de Vida no Trabalho dos Professores da Rede Federal de Educação Profissional e Tecnológica: percepções com a metodologia BPSO alinhado à qualidade da educação. Salvador: EnGPR, 2015.

PAIXÃO, R. B.; SOUZA, M. A.. A Percepção dos Docentes de Universidades Públicas Sobre a Qualidade de Vida no Trabalho. Brasília: EnGPR, 2013.

PAIVA, K. C. M.; COUTO, J. H.. Qualidade de vida e estresse gerencial 'pós-choque de gestão': o caso da Copasa-MG. Natal: EnGPR, 2007.

PAZINI, M. H.; STEFANO, S. R.. A Qualidade de Vida no Trabalho e Satisfação: um estudo multi-casos com os funcionários das empresas do sistema ' $S$ '. Curitiba: EnGPR,
2009.

PEIXOTO, N. H.. Segurança no trabalho. 3 ed. Santa Maria, 2011.

SCHIRMNEISTER, R.; LIMONGI FRANÇA, A. C.. Qualidade de Vida no Trabalho em Equipes Multicontratuais: um Estudo em um Instituto de Pesquisas Tecnológicas. Natal: EnGPR, 2007.

SILVA, L. B.; COSTA, M. S.. Relações de Trabalho em Organizações Não Governamentais. Curitiba: EnGPR, 2009.

SIMONI, E. M.; SILVA, M. A. M.. A Satisfação das Enfermeiras nas Organizações Hospitalares. Curitiba: EnGPR, 2009

SOUZA, E. P.; DIAS, M. A. M. J.; MARQUES, A. L.. Qualidade de Vida no Trabalho no Setor Público: diretrizes para a elaboração de um programa junto a um órgão da administração direta do Estado de Minas Gerais. Brasília: EnGPR, 2013.

STEFANO, S.; CAMPOS, E. A. R.; ANDRADE, S. M.. Análise dos níveis de estresse em formandos de administração e ciências contábeis em uma Universidade Pública. Salvador: EnGPR, 2015.

TAVARES, C. R. G.. Curso técnico em segurança do trabalho. Porto Alegre: UFRS, 2009.

VASCONCELOS, F.; DEMIER, M.; ABREU, M.; ALFERES, M.; NASCIMENTO, R. P.; SEGRE, L. M.. Estresse Ocupacional: Um estudo de Caso com Motoristas de Transporte Urbano do Município do Rio de Janeiro. Curitiba: EnGPR, 2009.

A CBPC - Companhia Brasileira de Produção Científica (CNPJ: 11.221.422/0001-03) detém os direitos materiais desta publicação. Os direitos referem-se à publicação do trabalho em qualquer parte do mundo, incluindo os direitos às renovações, expansões e disseminações da contribuição, bem como outros direitos subsidiários. Todos os trabalhos publicados eletronicamente poderão posteriormente ser publicados em coletâneas impressas sob coordenação da Sustenere Publishing, da Companhia Brasileira de Produção Científica e seus parceiros autorizados. Os (as) autores (as) preservam os direitos autorais, mas não têm permissão para a publicação da contribuição em outro meio, impresso ou digital, em português ou em tradução. 